\title{
Parenting with a smile: Display rules, regulatory effort, and parental burnout
}

\author{
Gao-Xian Lin ${ }^{1 *}$, Logan Hansotte ${ }^{1}$, Dorota Szczygieł ${ }^{2}$, Loes Meeussen ${ }^{3,4}$, \\ Isabelle Roskam ${ }^{1}$, and Moïra Mikolajczak ${ }^{1}$
}
${ }^{1}$ Psychological Sciences Research Institute, Department of Psychology, UCLouvain, Lou- vain-la-Neuve, Belgium
${ }^{2}$ SWPS University of Humanities and Social Sciences, Warszawa, Poland
${ }^{3}$ Center for Social and Cultural Psychology, KULeuven, Leuven, Belgium
${ }^{4}$ Research Foundation Flanders (FWO), Belgium

Short Title: Parenting with a smile

This article is a preprint.

\section{Author Note}

Logan Hansotte shares co-first authorship with Gao-Xian Lin.

*Corresponding Author

Gao-Xian Lin

Psychological Sciences Research Institute, Department of Psychology, Catholic University of Louvain, Place Cardinal Mercier, 10, Louvain-la-Neuve, 1348, Belgium

E-mail: gao-xian.lin@uclouvain.be 


\begin{abstract}
Positive parenting prescriptions prevailing in Western countries encourage parents to regulate their emotions and, more specifically, to show more positive emotion to their children and control negative emotions while parenting. The beneficial effect of this practice on child development has been much documented, but its possible costs for parents are currently unknown. The current study borrowed the well-known emotional labor framework from organizational psychology to examine this issue. We sought to answer five questions in particular:
\end{abstract} (1) Do parents perceive display rules? (i.e., do they feel pressured to up-regulate positive emotions and down-regulate negative emotions while parenting?) (2) Do parents make regulatory efforts to comply with these rules? (3) Is this costly? (4) Is it possible that this regulatory effort increases the risk of parental burnout? (5) Are there strategies that render this effort less costly? We investigated these questions in a sample of 347 parents. The results revealed that parents perceive emotional display rules, which bring about a regulatory effort and, in turn, increase vulnerability to parental burnout. How parents meet display rules also matters, in that regulating emotions superficially (surface acting, i.e., putting on a mask) is more detrimental than regulating genuinely (deep acting, i.e., changing one's emotion). Overall, these results confirm the potential of the emotional labor framework, which helps us understand how external pressures on parents increase parental burnout.

Keywords: parental burnout, emotional labor, emotional display rules, regulatory effort 
Parenting with a Smile: Display Rules, Regulatory Effort, and Parental Burnout

The goal of this study was to test the potential of a conceptual framework borrowed from affective science in organizational psychology, namely emotional labor, to shed light on a pressing yet under-researched question in parenting psychology: What are the down sides of positive parenting (if any)? Positive parenting consists of nurturing, valuing, empowering and structuring children in a non-violent way. Positive parents are expected to express positive emotions to their children and manage negative emotions (Chen, Haines, Charlton, \& VanderWeele, 2019; Le \& Impett, 2019; Le, Sakaluk, Day, \& Impett, 2018). While the benefits of positive parenting for children have been widely examined, its possible costs for parents have never been examined. Focusing on a core characteristic of positive parenting (i.e., emotional management), this study aimed to understand how costly it is for parents to manage their emotions to comply with positive parenting prescriptions.

The borrowing of the emotional labor framework to investigate this question is grounded in the fact that this framework has elegantly theorized the cost of emotion management at work, and that parenthood has a number of features that make it comparable to a job: (1) a number of external prescriptions as to how the parental role should be performed: what parents should do (e.g., be "positive" parents who provide their children with an emotionally secure environment, give them five helpings of fruit and vegetables a day, etc.), and what they should not do (e.g., use corporal or disproportionate punishment, put their very young 
children in front of screens, etc.), (2) expectations in terms of results (the child should be physically healthy, emotionally secure and up to date with schoolwork, behave politely, etc.), and (3) monitoring/control by the state, which checks whether parents are doing their job properly (via child health centers, school medical check-ups, etc.) and reserves the right to punish them and withdraw custody of the child as a last resort. Parents can no longer carry out their role as they see fit or just use "common sense" as they used to. Instead, they need to continuously adjust their behavior in accordance with society's prescriptions (Meeussen \& Van Laar, 2018).

The critical changes in parenting in recent decades (see the section on "Emotional Pressures on Parents" below for more details), and the increase in both parental pressure and parental engagement that have ensued, have coincided with the appearance of the notion of "parental burnout" (PB). Just as employees facing too much stress can end up in job burnout (see Maslach et al., 2001 for a review), parents under too much parental stress can end up in parental burnout (Mikolajczak, Gross, \& Roskam, 2019; Roskam, Raes, \& Mikolajczak, 2017). And, just as job burnout has severe consequences for the employee, his or her customers, and the company more generally, PB also has severe consequences for the parent, his or her children, and the family system more broadly (Mikolajczak, Brianda, Avalosse, \& Roskam, 2018; Mikolajczak et al., 2019). Preventing and treating PB requires a thorough understanding of 
the condition and of its determinants at the macro-, meso- and micro-levels and, most importantly, of the interplay between them. This study aimed to contribute to this work and to examine, in particular, the conditions under which external pressures on parents increase PB.

It is on this basis that we decided to borrow the emotional labor (EL) framework to study the costs of parents' efforts to manage their emotions in order to comply with positive parenting prescriptions (see below). This does not amount to reducing parenting to a job - it is obviously so much more than that — but the parallels between work and parenting that we mentioned earlier in the introduction legitimize the temporary adoption of this organizational framework to examine whether it facilitates the understanding of the effects of certain external pressures on parents. Importantly, this does not change the definition of EL (which remains emotion management "in exchange for wages"), nor does it reduce parental emotion regulation to the two flagship EL strategies (surface and deep acting).

\section{Emotional Pressures on Parents}

Society's views of children have changed drastically over the centuries, leading to a rapidly-growing expansion of the role and duties of parents. In the mid-19 ${ }^{\text {th }}$ century, various Western countries started to perceive children not only as unique and important, but also as fragile beings requiring extra efforts to protect (Hoghughi, 2004). This ideology became dominant after the Second World War, and was further fueled by both the birth of the welfare state and John Bowlby's views regarding the importance of the mother-child relationship 
(Bretherton, 1992). The concept of "child protection" has thus gradually been replaced by high-quality child-raising, with a supportive and warm family to ensure the child's harmonious development and fulfill its need for love and understanding (Hoghughi, 2004; Verhellen, 2000). This development has drastically affected the parental role, which now takes the form of a set of rules, normative recommendations, and prescriptions: these state that parents must not only take care of children's physical survival by ensuring proper nutrition, sleep, exercise and so on, but also bolster their subjective well-being, including their happiness, self-efficacy, and even purpose in life (Bornstein, 2015).

Emotional aspects of parenting are central to these prescriptions (for a recent study, see Carreras et al., 2019): parents must create a context of affective and relational safety for their children in order to make sure their children feel secure, loved and encouraged, and are allowed to develop and reach their full potential. Parents are therefore increasingly encouraged (or even required) to regulate their emotions during their parent-child interactions. As summarized in Dix's (1991) review, on the one hand, parents should refrain from too many negative emotions, like anxiety (which could make their relationship with their child insecure; e.g., Manassis et al., 1994) or anger; on the other hand, parents should also express positive emotions, like warmth, affection, happiness, gratitude, pride or wonder, to sustain the child's development and emotional security (e.g., Bai et al., 2016). This ideology is explicitly expressed in government policies (e.g., the Council of Europe's policy on positive parenting; 
Rodrigo, 2010; positive parenting tips provided by the National Center on Birth Defects and Developmental Disabilities (NCBDD), n.d.), which urge parents to be warm and supportive and to control their negative emotions, and is implicitly reinforced by social norms that condemn parents who are deemed to be inattentive, cold or too strict.

All these parenting strategies are embedded in the ideology of "positive parenting" (e.g., Sanders \& Mazzucchelli, 2017). The last few decades have seen the attachment of growing importance to research investigating the beneficial effects of positive parenting on child development (see Chen et al., 2019, for a review). In contrast, there has been relatively little research into the consequences of this set of parenting prescriptions for parents. How costly are these prescriptions for parents themselves? This study constituted a first attempt to investigate this question. Considering the central role of emotion in these positive parenting strategies, we focused on the rules that require parents to regulate their emotions. As explained earlier, the tenets of the emotional labor framework (e.g., Grandey, 2013) were therefore borrowed in order to examine whether these emotional display rules exist in parenting (whether parents perceive this prescription to down-regulate negative emotions and/or upregulate positive emotions in the presence of their children), and if so, whether and when these display rules contribute to exhausting parents and increase the risk of parental burnout. 


\section{The Notion of Emotional Labor}

The concept of emotional labor (EL) was proposed by Hochschild (1983) to designate the process of managing feelings and their expressions to fulfill the emotional requirements of a job (i.e., to meet the emotional display rules or, in Hochschild's terms, the "feeling rules" of the workplace). Emotional display rules incorporate information about "which" and "how" emotions should be managed "where" and "when."

According to Hochschild (1983), EL is said to occur when: (1) employees are in direct contact with customers ("voice to voice" or "face to face"), (2) the organization explicitly or implicitly specifies which emotions must/can be expressed and how they have to be expressed (e.g., via training, organizational culture, or precepts such as "Put a smile in your voice"), and (3) the organization directly or indirectly controls its employees' emotional expressions. Such emotional display rules create a pressure towards emotion management (i.e., stimulate a regulatory effort) whenever employees' inner and required emotions do not match, i.e., whenever employees find themselves in a situation of emotional dissonance.

According to the tenets of the EL framework, employees perform this regulatory effort mainly using two strategies: surface acting and deep acting. The former refers to bringing the outward expression of emotion in line with the display rules (e.g., suppressing anger and/or putting on a fake smile); the latter consists of attempts to deeply modify internal feelings to 
align felt and required emotions (e.g., reappraising an event and finding a way to feel and ex-

press positive emotion sincerely). These original definitions imply that these two strategies of emotional labor are independent of one another (Mikolajczak, Menil, \& Luminet, 2007), but most empirical research has shown that they may positively intercorrelate (e.g., Grandey, 2003) and may be enacted in tandem (Gabriel, Daniels, Diefendorff, \& Greguras, 2015).

\section{Emotional Labor and Job Burnout}

Hochschild (1983, p. 90) borrowed the idea of "alienation" from Karl Marx to propose that emotional display rules put employees at risk of emotional dissonance, which leads to self-estrangement, distress, and even job burnout if EL is too frequent (see Wharton, 2009). This proposition has been largely supported. A recent meta-analysis showed that emotional display rules predicted the frequency of both surface and deep acting (Kammeyer-Mueller et al., 2013), which further predicted employees' (lower) well-being and even burnout (e.g., exhaustion, one of the core symptoms in burnout; Hülsheger \& Schewe, 2011). Incorporating these concepts in the same research, Goldberg and Grandey (2007) simulated an incoming call center and manipulated the different levels of display rules (with or without explicit rules). Their results confirmed the theoretical mechanism of emotional labor, indicating that emotional display rules predict exhaustion through the mediation pathway of emotional labor acting. 
However, the two means of emotional labor do not seem to have equivalent conse-

quences. While most studies on emotional labor reveal that surface acting reliably and consistently predicts job burnout (Hülsheger \& Schewe, 2011), the effect of deep acting is not as consistent across studies. Although some studies have shown a damaging effect of deep acting (though still less harmful than surface acting; e.g., Mikolajczak et al., 2007), most studies have found that it was neither positively nor negatively related to burnout (e.g., Brotheridge \& Lee, 2002; Hülsheger \& Schewe, 2011).

The concept of "regulatory effort" could explain the different consequences of surface and deep acting. Although surface and deep acting are both effortful, the amount of regulatory effort they require differs (e.g., Grandey, 2003), which is congruent with previous findings in the emotion regulation field showing that suppression is less efficient at managing emotions than reappraisal, because of the extra need for sustained regulatory effort over time (e.g., (Goldin, McRae, Ramel, \& Gross, 2008; Gross, 1998; McRae, 2016; Richards \& Gross, 1999, 2000). If individuals depend more on surface acting to meet organizations' display rules, their effort and cognitive resources are more heavily drained in order to monitor their emotional expression continually, suppress emotions that cannot be shown and/or fake emotions that need to be shown. Continuous resource-draining in the end causes strain and burnout (Brotheridge \& Grandey, 2002). In contrast, although deep acting also requires cognitive 
resources to manage emotions, these efforts are needed only at the onset of emotion, which would explain its weaker predictive association with job burnout.

\section{Using the Emotional Labor Framework to Understand Parental Burnout}

As described earlier, parents are now increasingly expected to regulate their emotions to be deemed "good," "positive," and "secure" parents (also see Ryan et al., 2006, p.212). At the same time, parents seem increasingly exhausted by their parenting role, at least in Western countries (Roskam et al., 2020). Parental burnout is usually described as encompassing four core symptoms: intense exhaustion resulting from one's parental role, perceived saturation with one's parental role, emotional distancing from one's child(ren), and perceived contrast between previous and current parental self (Roskam, Brianda, \& Mikolajczak, 2018). These symptoms are theorized to develop because of a chronic imbalance between parentingrelated demands and available resources (Mikolajczak \& Roskam, 2018). Among multiple factors, cultural factors have recently been shown to weigh heavily, with Western parents being five times more vulnerable to parental burnout than parents in the rest of the world (Roskam et al., 2020). Based on this result and knowing that "positive parenting" is currently particularly prevalent in Western countries, we suggest that one of the factors depleting parents' resources is their perception of emotional display rules in parenting and the means of emotional labor they utilize to comply with these rules. 
As positive parenting urges parents to both express warmth and other supportive emotions and control negative emotions, the present study used the emotional labor framework to examine five questions: (1) Do parents perceive emotional display rules in their parenting?

(2) How much effort is required for parents to comply with these emotional display rules? (3)

Do parents comply with these emotional display rules by using surface and deep acting? (4)

Does this emotional management require regulatory efforts? (5) Is it possible that these regulatory efforts increase the risk of parental burnout? Following previous research in organization literature regarding emotional labor, we proposed that perceived emotional display rules lead to surface acting and deep acting, which require effort and eventually increase parental burnout (see Figure 1). A number of hypotheses were therefore tested in this study:

Hypothesis 1: Parents perceive emotional display rules in parenting.

Hypothesis 1a: Parents perceive that they are required to show positive emotions in parenting.

Hypothesis 1b: Parents perceive that they are required to control negative emotions in parenting.

Hypothesis 2: It requires effort from parents to comply with emotional display rules.

Hypothesis 2a: It requires effort from parents to show positive emotions in parenting.

Hypothesis $2 \mathrm{~b}$ : It requires effort from parents to control negative emotions in parenting. Hypothesis 3: Parents comply with emotional display rules by using surface and deep acting. 
Hypothesis 3a: Perceived display rules positively predict surface acting.

Hypothesis 3b: Perceived display rules positively predict deep acting.

Hypothesis 3c: Surface acting positively correlates with deep acting.

Hypothesis 4: Emotion management in response to display rules is effortful.

Hypothesis 4a: Surface acting positively predicts regulatory effort.

Hypothesis 4b: Deep acting positively predicts regulatory effort.

Hypothesis 4c: The predictive effect of deep acting on regulatory effort is lower than the effect of surface acting.

Hypothesis 5: The regulatory efforts involved in complying with emotional display rules increase vulnerability to parental burnout.

Hypothesis 5a: Regulatory effort predicts parental burnout.

Hypothesis 5b: Both surface acting and deep acting positively predict parental burnout because of the regulatory efforts they require.

Hypothesis 5c: Emotional display rules predict parental burnout because of the indirect effect of the effort put into surface/deep acting.

Hypothesis 5d: The indirect effect of deep acting on parental burnout due to regulatory effort is smaller than the indirect effect of surface acting on parental burnout due to regulatory effort. 


\section{Method}

\section{Participants and Procedure}

The study protocol, as well as the information and written consent documents, were approved by the Institutional Review Board. The study was posted online on Qualtrics. Parents were informed about the survey through social networks, websites, schools, pediatricians, or word of mouth. They were eligible to participate only if they had (at least) one child still living at home. Of the 379 people who responded to the survey, 32 provided incomplete data. As an independent-samples t-test revealed no significant mean difference of the main variables used in the analysis between these participants and the others, they were all listwise deleted. The final sample consisted of 347 parents $\left(M_{\text {age }}=38.75\right.$ years, $S D_{\text {age }}=9.77$ years; 30 fathers and 317 mothers). The majority came from France (48.4\%) and Belgium (42.9\%), a minority from Luxemburg (5\%) and other European countries (1\%), and the rest from non-European countries $(0.01 \%) .53 .9 \%$ worked full-time, $10.7 \%$ worked half-time, $18.2 \%$ worked parttime, and $17.2 \%$ did not work for various reasons (e.g., homemaker). 50.7\% were married, $38.0 \%$ were legally cohabiting, and $11.2 \%$ were single parents. Overall, the participants had from 1 to 7 children. Their oldest child aged from 0 to 42 years $\left(M_{\text {age }}=10.58\right.$ years; $S D_{\text {age }}=$ 9.75 years), and $50.7 \%$ of them were boys. Among the participants, $0.6 \%$ were educated to primary level, $13.5 \%$ were educated to secondary level, $76.4 \%$ had a bachelor's or a master's degree, and 9.5\% had a Ph.D. or an MBA degree. Income was distributed as follows: $24.2 \%$ 
had a net monthly household income lower than $€ 2500,39.5 \%$ between $€ 2500$ and $€ 4000$, $17.6 \%$ between $€ 4000$ and $€ 5500$, and $18.8 \%$ higher than $€ 5500$.

\section{Measures}

Sociodemographic factors. Participants answered questions regarding their age, gender, marital status, net monthly household income, level of education, work regime, number of children, and the gender and age of each child.

Parental burnout. Participants completed the Parental Burnout Assessment (PBA) (Roskam et al., 2018), which is currently the gold-standard measure of parental burnout. It includes 23 items rated on a 7-point frequency scale (never (0), a few times a year or less (1), once a month or less (2), a few times a month (3), once a week (4), a few times a week (5), every day (6)). The PBA is organized into four subscales: Exhaustion in one's parental role (9 items; e.g., I feel completely run down by my role as a parent), Emotional distancing from one's child(ren) (3 items; e.g., I do what I'm supposed to do for my child(ren), but nothing more), Feelings of being fed up with one's parental role (5 items; e.g., I can't stand my role as father/mother any more), and Contrast with previous parental self (6 items; e.g., I don't think I'm the good father/mother that I used to be to my child(ren)). These four subscales are summed to form a global score. The Cronbach's $\alpha$ s in the current sample were .97 for the global scale and $.80-.97$ for the four subscales.

Perceived emotional display rules in parenting. A questionnaire to measure emotional 
display rules was created for the purpose of the present study based on a pilot survey run on another sample of parents $(N=166)$. This pilot survey included both open-ended and closeended questions (in that order) about which emotions parents thought they needed to show in front of their children and which emotions they thought they needed to control. The emotions mentioned most frequently in the pilot study were extracted to constitute the Perceived Emotional Display Rules in Parenting Scale. Because most parents reported in the pilot study that what they needed to show in front of their children were positive emotions and what they needed to control were negative emotions, we restricted the formal questionnaire to the assessment of "showing positive emotions" and "controlling negative emotions." This formal questionnaire thus measured emotional display rules concerning both showing positive emotions (9 emotion items; e.g., "A parent must be loving towards his/her child") and controlling negative emotions (10 emotions items; e.g., "A parent must control his/her stress in the presence of his/her child"). Items were rated on a 5-point Likert scale (strongly disagree (0), disagree (1), neither agree nor disagree (2), agree (3), strongly agree (4)). Positive emotions included loving, joyful, happy, serene, proud, compassionate, careful, enthusiastic, while negative emotions included stress, irritation, anxiety, sadness, anger, fear, hopelessness, distress, discouragement. The global score was obtained by summing up all items. The Cronbach's $\alpha$ of the global score in the current sample was .90 (.85 for positive emotions and .89 for negative emotions). 


\section{Regulatory effort required to comply with perceived display rules in parenting. The}

items from the Perceived Emotional Display Rules in Parenting Scale were reframed to assess the perceived amount of effort it took to regulate these emotions to align with the emotional display rules. This questionnaire measured the regulatory effort of both showing positive emotions ( 9 emotion items; e.g., How much effort does it require from me to show my love towards my child?) and controlling negative emotions (10 emotion items; e.g., How much effort does it require from me to control my stress in the presence of my child?) on a 6point Likert scale (not applicable (0), no effort at all (1), little effort (2), average effort (3), lots of effort (4), huge effort (5)). A global score was obtained by summing up all items. The Cronbach's $\alpha$ in the current sample was .92 for the global scale (.86 for positive emotions and .90 for negative emotions).

Emotional labor. Parents' surface and deep acting were measured using an adaptation of the Emotional Labour Scale (Brotheridge \& Lee, 1998; Brotheridge \& Grandey, 2002) to parenting. This questionnaire included six items rated on a 5-point frequency scale (never (1), rarely (2), sometimes (3), often (4), always (5)), organized into two subscales: surface acting (SA; 3 items, e.g., "In the presence of my child, I try not to express my true feelings"), referring to hiding and faking expressions of emotion, and deep acting (DA; 3 items, e.g., "In the presence of my child, I try to really feel the emotions I think it is necessary to express as a parent"), referring to modifying feelings to comply with display rules in parenthood. The 
Cronbach's $\alpha$ in the current sample were .73 for SA and .93 for DA.

\section{Analytic Strategy}

First of all, hypothesis 1 was tested with one-sample t-tests conducted with IBM SPSS

25.0 (IBM Corp., 2017). Specifically, we compared the mean of the average score (the sum of all items divided by the number of items) of perceived emotional display rule with the scale value that represented no perceived emotional display rule (scale value $=0$ [strongly disagree] and scale value 2 [neither agree nor disagree]). In a similar vein, we also compared the mean of the average score of regulatory effort with the scale value $=1$ (no effort at all).

Next, hypotheses 3-5 were examined via correlations and via path analysis conducted with STATA 16.0 (StataCorp., 2019). The path analysis model was run with maximum likelihood estimation. Although this estimation is relatively robust to deviations from multivariate normality, standard errors and model-fitting indices could still be biased. Therefore, the Satora-Bentler correction was used to adjust all the goodness-of-fit statistics involving the likelihood-ratio test comparing the fitted model with the saturated model. For the sake of simplicity, we only present the model that represents parental burnout with its global score. A model where parental burnout is represented by its four subscales is presented in the Supplementary Material (see Table S1 and Figure S1); this model yields similar results to those of the model using the global parental burnout score). Evaluation of the fit of the models was carried out on the basis of inferential goodness-of-fit statistics $\left(\chi^{2} ; \mathrm{Hu} \&\right.$ Bentler, 1998) and four other 
indices: the comparative fit index (CFI), the Tucker-Lewis Index (TLI), the root mean square error of approximation (RMSEA), and the standardized root mean square residual (SRMR). Values close to or greater than .95 are desirable on the CFI and TLI (Hu \& Bentler, 1999), while both the RMSEA and SRMR should preferably be lower than .08 (Browne \& Cudeck, 1992; Hu \& Bentler, 1999).

We evaluated the size of the sample according to the ratio of cases $(N)$ to the number of path analysis model parameters that require statistical estimates $(q)$, which should be over 20:1 (Kline, 2011). Given that we would have 11 parameters in our path analysis, we needed a sample size of at least 220 participants. Recruitment efforts were thus maintained until we reached that sample size. In the end, our efforts led to even larger sample size than needed $(\mathrm{N}: \mathrm{q}=347: 11)$. De-identified data are publicly available via the Open Science Framework and can be accessed at https://osf.io/sauqh/?view_only=4386ebd4ed9d41b0ba91be2eda407bac.

\section{Results}

\section{Parents Perceive Emotional Display Rules in Parenting}

Descriptive statistics and correlations among study variables are shown in Table 1.

Means and standard deviations of each item of the scale "Perceived Emotional Display Rules in Parenting" are shown in Table 2 (left columns). As shown in this table, on average, parents agreed on the existence of emotional display rules in parenting (means of all items exceeded score value $=2$, "neither agree nor disagree"). Mean comparison with scale value 0 and with 
scale value 2 also supported the existence of emotional display rules in parenting: the average score of global emotional display rules of parenting $(M=2.98, S D=0.47)$ was significantly higher $(t(346)=118.33, p=.000, d=6.34,95 \%$ CI of mean difference $[2.93,3.03])$ than the scale value $=0$ (strongly disagree $)$ and significantly higher $(t(346)=38.86, p=.000, \mathrm{~d}=$ $2.09,95 \% \mathrm{CI}$ of mean difference $[0.93,1.03])$ than the scale value $=2$ (neither agree nor disagree). The same was true for the subscale "showing positive emotions" (mean comparison with scale value $=0: M=3.06, S D=0.52 ; t(346)=109.49, p=.000, d=5.88,95 \% \mathrm{CI}$ of mean difference $[3.00,3.11]$; mean comparison with scale value $=2: t(346)=37.82, p=.000$, $d=2.04,95 \%$ CI of mean difference $[1.00,1.11])$ and for the subscale "controlling negative emotions" (mean comparison with scale value $=0: M=2.91, S D=0.57 ; t(346)=94.56, p$ $=.000, d=5.11,95 \% \mathrm{CI}$ of mean difference [2.85, 2.97]; mean comparison with scale value $=2: t(346)=29.53, p=.000, d=1.59,95 \% \mathrm{CI}$ of mean difference [0.85, 0.97]). Hypotheses $1 \mathrm{a}$ and $1 \mathrm{~b}$ were thus supported.

\section{It Requires Effort from Parents to comply with Emotional Display Rules}

As shown in Table 2 (right columns), parents indicated that they made efforts to comply with emotional display rules in parenting (means of all items exceeded score value $=1$, "No effort at all"). Comparison of mean regulatory effort with scale value $=1$ validated this observation: parents' average amount of effort for their emotion regulation in parenting $(M=2.01$, $S D=0.72)$ was significantly higher than $1(t(346)=25.98, p<.001, d=1.40,95 \% \mathrm{CI}$ of the 
difference $[0.93,1.09])$. The same was true for the subscales "showing positive emotions" $(M$

$=1.70, S D=0.66 ; t(346)=19.78, p<.001, d=2.03,95 \% \mathrm{CI}$ of mean difference $[0.63$,

$0.77])$ and "controlling negative emotions" $(M=2.29, S D=0.93 ; t(346)=25.96, p<.001, d$

$=1.39,95 \% \mathrm{CI}$ of mean difference $[1.19,1.39])$. Thus, hypotheses $2 \mathrm{a}$ and $2 \mathrm{~b}$ were also sup-

ported.

\section{Parents Comply with Emotional Display Rules by Using Surface and Deep Acting}

As shown in Table 1, perceived emotional display rules positively correlated with both surface acting $(r(346)=.25, p=.000)$ and deep acting $(r(346)=.23, p=.000)$. Hypotheses $3 \mathrm{a}$ and $3 \mathrm{~b}$ were thus supported. Hypothesis $3 \mathrm{c}$ was also supported, in that surface acting positively correlated with deep acting $(r(346)=.28, p=.000)$.

\section{Emotion Management in Response to Display Rules is Effortful}

As shown in Table 1, both surface acting $(r(346)=.41, p=.000)$ and deep acting $(r(346)$ $=.25, p=.000)$ positively correlated with regulatory effort, thereby supporting hypotheses $4 \mathrm{a}$ and $4 \mathrm{~b}$. Comparison of the correlation coefficients indicated that the effect of deep acting on regulatory effort was lower than the effect of surface acting $(z=2.36, p=.009)$, thereby supporting hypothesis $4 \mathrm{c}$.

The Regulatory Efforts Involved in Complying with Emotional Display Rules Increase

\section{Vulnerability to Parental Burnout}


As shown in Table 1, regulatory effort positively correlated with parental burnout $(r(346)$ $=.59, p=.000)$, thereby supporting hypothesis $5 \mathrm{a}$. Mediation hypotheses $5 \mathrm{~b}$ to $5 \mathrm{~d}$ were supported by the path analysis model shown in Figure 1 (all coefficients are summarized in Table $3)$ : although the chi-square $\left(\chi^{2}(4)=10.40, p=.034\right)$ of our path analysis was significant, the other fit indices suggested that the proposed model had a good fit to the data (CFI $=.97$, TLI $=.93, \mathrm{RMSEA}=.07, \mathrm{SRMR}=.03)$. Path coefficients were all significant in the proposed direction, and the relation between surface acting and regulatory effort was higher than the relation between deep acting and regulatory effort $\left(\chi^{2}(1)=6.89, p=.009\right)$. The predicted relations delineated in hypotheses 3-4 and 5a were thereby all validated. Moreover, the indirect effects of perceived emotional display rules (via surface acting/deep acting and the regulatory effort they involved), surface acting (via regulatory effort), and deep acting (via regulatory effort) on parental burnout were all significant $(p s<.05)$. Among them, the standardized indirect effect of surface acting was, as expected, higher than deep acting (difference $=6.61, S E=1.88, z=$ $3.51, p=.000,95 \%$ CI $[2.92,10.30])$.

\section{Discussion}

Applying the emotional labor (EL) framework from organizational psychology to parenting, this study aimed to improve our understanding of the consequences of some tenets of positive parenting (e.g., Sanders \& Mazzucchelli, 2017) for Western parents. A path analysis model, which integrated all proposed paths in reference to previous organizational literature 
(e.g., Brotheridge \& Grandey, 2002; Brotheridge \& Lee, 2002; Goldberg \& Grandey, 2007;

Grandey, 2003), supported the relevance of using the EL framework and uncovered some of the mechanisms by which current "parenting culture" (Lee, Bristow, Faircloth, \& Macvarish, 2014) puts parents under pressure. This model revealed that parents perceive emotional display rules (i.e., the need to express positive emotions and control negative emotions in front of their children), which bring about a regulatory effort and, in turn, increase vulnerability to parental burnout.

These results contribute to both parenting and EL literature. As far as parenting is concerned, our results highlight that although positive parenting has very beneficial effects for children (e.g., Chen et al., 2019), it comes at a cost for parents. At a time in history when the prevalence of parental burnout in Western countries (the very same countries in which the positive parenting model prevails) is preoccupying (and five times greater than in other parts of the world; Roskam et al., 2020), the present study constitutes a call for researchers in parenting to find ways to prevent the well-being of children coming at the expense of that of parents. Just as organizational psychology put huge research efforts into trying to find ways of reconciling the interests of clients with the well-being of employees, the reconciliation of the well-being of children with that of parents appears to be a promising and fertile avenue for future research in parenting psychology. This is especially important because previous research has shown that positive parenting might eventually backfire on children whose parents 
have exhausted themselves (Brianda et al., 2020) in the pursuit of parenting perfection (Sorkkila \& Aunola, 2020). Thus, ironically, positive parenting might ultimately have a negative effect on those whom it seeks to protect.

Although this study was not intended to contribute to the EL literature, it does in some ways. First, it confirms the potential of the EL theoretical framework, which has already given rise to thousands of studies in organizational psychology. Second, it confirms that, although deep acting can be costly, the effort it requires is less than that of surface acting (e.g., Brotheridge \& Grandey, 2002; Hülsheger \& Schewe, 2011; Sayre et al., 2019). These results are certainly worth investigating further, as they stand in stark contrast with the facial feedback hypothesis (Strack, Martin, \& Stepper, 1988), which states that the facial expression of an emotion (e.g., a faked smile) prompts the corresponding feeling (i.e., happiness). Lastly, given the emerging evidence of the spillover of EL across different domains (e.g., SanzVergel et al., 2012), future research could examine the association and even interaction between EL at work and regulatory efforts to comply with display rules in parenting: employees who are also well-intentioned parents may bear the highest risk of adverse consequences.

\section{Limitation and Future Directions}

In spite of its strengths, this study suffers from several limitations that need to be acknowledged. The first limitation lies in the sample: most respondents were mothers. It is therefore unclear whether fathers equally perceive display rules and, if so, whether they also 
constitute a vulnerability factor vis-à-vis parental burnout for them. Future studies would benefit from going deeper into this issue. The second limitation lies in the design, which is both cross-sectional and self-reported, resulting in higher shared variance. Future studies that manipulate emotional display rules in the same way as in Goldberg and Grandey's (2007) simulation would be useful. Moreover, the measure of parental burnout could be supplemented with psychobiological indicators of stress, such as cortisol (e.g., Lim et al., 2018) or autonomous nervous system activation measurements (e.g., de Looff et al., 2018).

Despite the above-mentioned limitations, our research opens exciting new directions in parenting psychology. One future direction is to reconcile the well-being of children with that of parents. This can be achieved either by investigating how parents can live up to positive parenting without exhausting themselves (e.g., good co-parental support) or by looking into ways in which parents can express their true positive/negative feelings without negatively affecting children (which could actually increase children's emotional competence). The other future direction would consist of probing the significant correlation between surface acting and deep acting, which raises the possibility of different subpopulations of parents with distinct combinations of surface and deep acting, possibly associated with different outcomes, as shown by Gabriel et al.'s (2015) study of workers. Adopting a person-centered approach in future research, for example through a latent profile analysis, could allow us to identify profiles of parents and examine their association with outcomes. 
Another exciting and essential future direction would consist in going beyond the two flagship strategies of the emotional labor framework and investigating the costs and benefits of other emotion regulation strategies that parents may use to comply with emotional display rules. One well-founded model for this is the process model of emotion regulation (PMER; Gross, 1998a, 2014) — the dominant model in the emotion regulation research field — which has already been used to expand the EL framework in the organizational domain (Grandey, 2000; Mikolajczak, Tran, Brotheridge, \& Gross, 2009). Pursuing the investigation of the impact of parents' emotion regulation in their parental role and its impact on their well-being using this model (or its broadened version, the Extended PMER; Gross, 2015) might prove particularly fruitful.

\section{Final Remark}

Positive parenting puts parents under pressure. The present study used the emotional labor framework to improve our understanding of the emotional aspects of that pressure and their consequences for parents. Our findings show that the perceived pressure to show positive emotions and control negative emotions drains parents' resources and increases their vulnerability to parental burnout. Beyond this, our findings support the relevance of cross-fertilization among subdisciplines in psychology: a theoretical framework from one subdiscipline can enrich another, seemingly distant subdiscipline. 
Table 1

Descriptive Statistics and Correlation Among Study Variables

\begin{tabular}{|c|c|c|c|c|c|c|c|c|c|c|c|c|c|c|}
\hline & Variables & $M(S D)$ & 1 & 2 & 3 & 4 & 5 & 6 & 7 & 8 & 9 & 10 & 11 & 12 \\
\hline 1 & Display rule (show positive) & $27.50(4.68)$ & & & & & & & & & & & & \\
\hline 2 & Display rule (control negative) & $29.08(5.73)$ & $.46^{* *}$ & & & & & & & & & & & \\
\hline 3 & Display rule & $56.58(8.91)$ & $.82^{* *}$ & $.88^{* *}$ & & & & & & & & & & \\
\hline 4 & Regulatory effort (show positive) & $15.28(5.92)$ & $.12^{*}$ & $.16^{* *}$ & $.16^{* *}$ & & & & & & & & & \\
\hline 5 & Regulatory effort (control negative) & $22.93(9.28)$ & $.11^{*}$ & $.22^{* *}$ & $.20^{* *}$ & $.63^{* *}$ & & & & & & & & \\
\hline 6 & Regulatory effort & $38.21(13.77)$ & $.13^{*}$ & $.22^{* *}$ & $.21^{* *}$ & $.85^{* *}$ & $.94^{* *}$ & & & & & & & \\
\hline 7 & Surface acting & $2.07(0.68)$ & $.19^{* *}$ & $.23^{* *}$ & $.25^{* *}$ & $.39^{* *}$ & $.36^{* *}$ & $.41^{* *}$ & & & & & & \\
\hline 8 & Deep acting & $2.91(1.21)$ & $.29^{* *}$ & $.12^{*}$ & $.23^{* *}$ & $.19^{* *}$ & $.25^{* *}$ & $.25^{* *}$ & $.28^{* *}$ & & & & & \\
\hline 9 & Exhaustion in parental role & $12.51(12.29)$ & $.11^{*}$ & .10 & $.12^{*}$ & $.55^{* *}$ & $.48^{* *}$ & $.56^{* *}$ & $.34^{* *}$ & $.13^{*}$ & & & & \\
\hline 10 & Contrast in parental self & $5.07(7.19)$ & .06 & $.11^{*}$ & .10 & $.56^{* *}$ & $.49^{* *}$ & $.57^{* *}$ & $.32^{* *}$ & $.16^{* *}$ & $.80^{* *}$ & & & \\
\hline 11 & Feelings of being fed up & $4.24(5.76)$ & .05 & .04 & .05 & $.56^{* *}$ & $.47^{* *}$ & $.56^{* *}$ & $.31^{* *}$ & $.12^{*}$ & $.89^{* *}$ & $.81^{* *}$ & & \\
\hline 12 & Emotional distancing & $2.33(3.19)$ & .02 & .02 & .02 & $.52^{* *}$ & $.37^{* *}$ & $.47^{* *}$ & $.28^{* *}$ & .07 & $.70^{* *}$ & $.68^{* *}$ & $.78^{* *}$ & \\
\hline 13 & Global parental burnout & $24.14(26.37)$ & .08 & .09 & .10 & $.59^{* *}$ & $.50^{* *}$ & $.59^{* *}$ & $.35^{* *}$ & $.14^{* *}$ & $.96^{* *}$ & $.91^{* *}$ & $.95^{* *}$ & $.80^{* *}$ \\
\hline
\end{tabular}

${ }^{*} p \leq .05 .{ }^{* *} p \leq .01$. 
Table 2

Mean and Standard Deviation of Each Item of Perceived Emotional Display Rule and Regu-

latory Effort

\begin{tabular}{|c|c|c|c|c|}
\hline \multirow[t]{2}{*}{ Scales/Items } & \multicolumn{2}{|c|}{ Emotional Display Rule } & \multicolumn{2}{|c|}{ Regulatory Effort } \\
\hline & $M$ & $S D$ & $M$ & $S D$ \\
\hline Show positive emotions (global) ${ }^{a}$ & 3.06 & 0.52 & 1.70 & 0.66 \\
\hline Love & 3.63 & 0.64 & 1.27 & 0.70 \\
\hline Joy & 2.51 & 0.87 & 1.84 & 1.00 \\
\hline Happy & 2.58 & 0.86 & 1.76 & 1.04 \\
\hline Serene & 2.97 & 0.78 & 2.29 & 1.11 \\
\hline Proud & 3.34 & 0.75 & 1.28 & 0.73 \\
\hline Compassionate & 3.28 & 0.71 & 1.47 & 0.80 \\
\hline Attentive & 3.56 & 0.57 & 1.99 & 1.01 \\
\hline Enthusiastic & 2.88 & 0.81 & 1.80 & 1.05 \\
\hline Satisfied & 2.77 & 0.86 & 1.60 & 1.03 \\
\hline Control negative emotions (global) ${ }^{b}$ & 2.91 & 0.57 & 2.29 & 0.93 \\
\hline Stress & 3.01 & 0.67 & 2.83 & 1.05 \\
\hline Irritation & 3.15 & 0.70 & 3.04 & 1.12 \\
\hline Anxiety & 3.03 & 0.71 & 2.56 & 1.26 \\
\hline Sadness & 2.28 & 1.01 & 2.23 & 1.29 \\
\hline Anger & 3.04 & 0.85 & 2.63 & 1.26 \\
\hline Fear & 2.68 & 0.88 & 2.09 & 1.18 \\
\hline Hopelessness & 3.00 & 0.79 & 1.71 & 1.46 \\
\hline Distress & 2.75 & 0.82 & 1.80 & 1.31 \\
\hline Discouragement & 2.76 & 0.85 & 2.07 & 1.29 \\
\hline Rage & 3.40 & 0.79 & 1.98 & 1.51 \\
\hline
\end{tabular}

a Average score of the subscale "show positive emotions" (the summed score of all items divided by the number of items).

${ }^{\mathrm{b}}$ Average score of the subscale "control negative emotions" (the summed score of all items divided by the number of items). 
Table 3

Coefficients and Indirect Effect of Path Analysis Model of Associations Between Emotional

Display Rule, Surface/Deep Acting, Regulatory Effort, and Parental Burnout

\begin{tabular}{|c|c|c|c|c|c|c|c|}
\hline \multirow{2}{*}{ Relations } & \multirow{2}{*}{$\begin{array}{c}\text { Std. } \\
\text { estimate }\end{array}$} & \multirow{2}{*}{$\begin{array}{l}\text { Unstd. } \\
\text { estimate }\end{array}$} & \multirow{2}{*}{$S E^{\mathrm{a}}$} & \multirow{2}{*}{$\mathrm{z}$} & \multirow{2}{*}{$p$} & \multicolumn{2}{|c|}{$95 \% \mathrm{CI}$} \\
\hline & & & & & & $L L$ & $U L$ \\
\hline \multicolumn{8}{|l|}{ Path coefficient } \\
\hline $\begin{array}{l}\text { Display rule } \rightarrow \text { Surface } \\
\text { acting }\end{array}$ & .25 & 0.02 & 0.00 & 5.07 & .000 & 0.01 & 0.03 \\
\hline $\begin{array}{l}\text { Display rule } \rightarrow \text { Deep act- } \\
\text { ing }\end{array}$ & .23 & 0.03 & 0.01 & 4.13 & .000 & 0.02 & 0.05 \\
\hline $\begin{array}{l}\text { Surface acting } \rightarrow \\
\text { Regulatory effort }\end{array}$ & .37 & 7.48 & 1.00 & 7.45 & .000 & 5.51 & 9.44 \\
\hline $\begin{array}{l}\text { Deep acting } \rightarrow \\
\text { Regulatory effort }\end{array}$ & .15 & 1.66 & 0.58 & 2.87 & .004 & 0.53 & 2.80 \\
\hline $\begin{array}{l}\text { Regulatory effort } \rightarrow \\
\text { Global parental burnout }\end{array}$ & .59 & 1.14 & 0.13 & 8.82 & .000 & 0.88 & 1.39 \\
\hline \multicolumn{8}{|l|}{ Covariance } \\
\hline $\begin{array}{l}\text { Error (Surface acting) } \leftrightarrow \\
\text { Error (Deep acting) }\end{array}$ & .24 & 0.18 & 0.04 & 4.16 & .000 & 0.10 & 0.27 \\
\hline \multicolumn{8}{|l|}{ 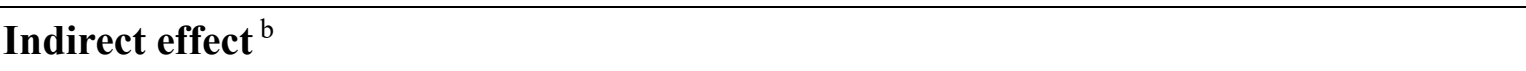 } \\
\hline $\begin{array}{l}\text { Surface acting } \rightarrow \\
\text { Global parental burnout }\end{array}$ & .22 & 8.50 & 1.68 & 5.05 & .000 & 5.20 & 11.80 \\
\hline $\begin{array}{l}\text { Deep acting } \rightarrow \\
\text { Global parental burnout }\end{array}$ & .09 & 1.89 & 0.65 & 2.91 & .004 & 0.62 & 3.16 \\
\hline $\begin{array}{l}\text { Display Rule } \rightarrow \\
\text { Global parental burnout }\end{array}$ & .07 & 0.22 & 0.06 & 3.98 & .000 & 0.11 & 0.33 \\
\hline
\end{tabular}

Note. Std. estimate $=$ standardized estimate; Unstd. estimate $=$ unstandardized estimate; $\mathrm{CI}=$

confidence interval; $L L=$ lower limit; $U L=$ upper limit.

${ }^{a} S E$ was adjusted by Satorra-Bentler adjustments.

${ }^{\mathrm{b}}$ Indirect effect testing was calculated by Satorra-Bentler adjustments. 


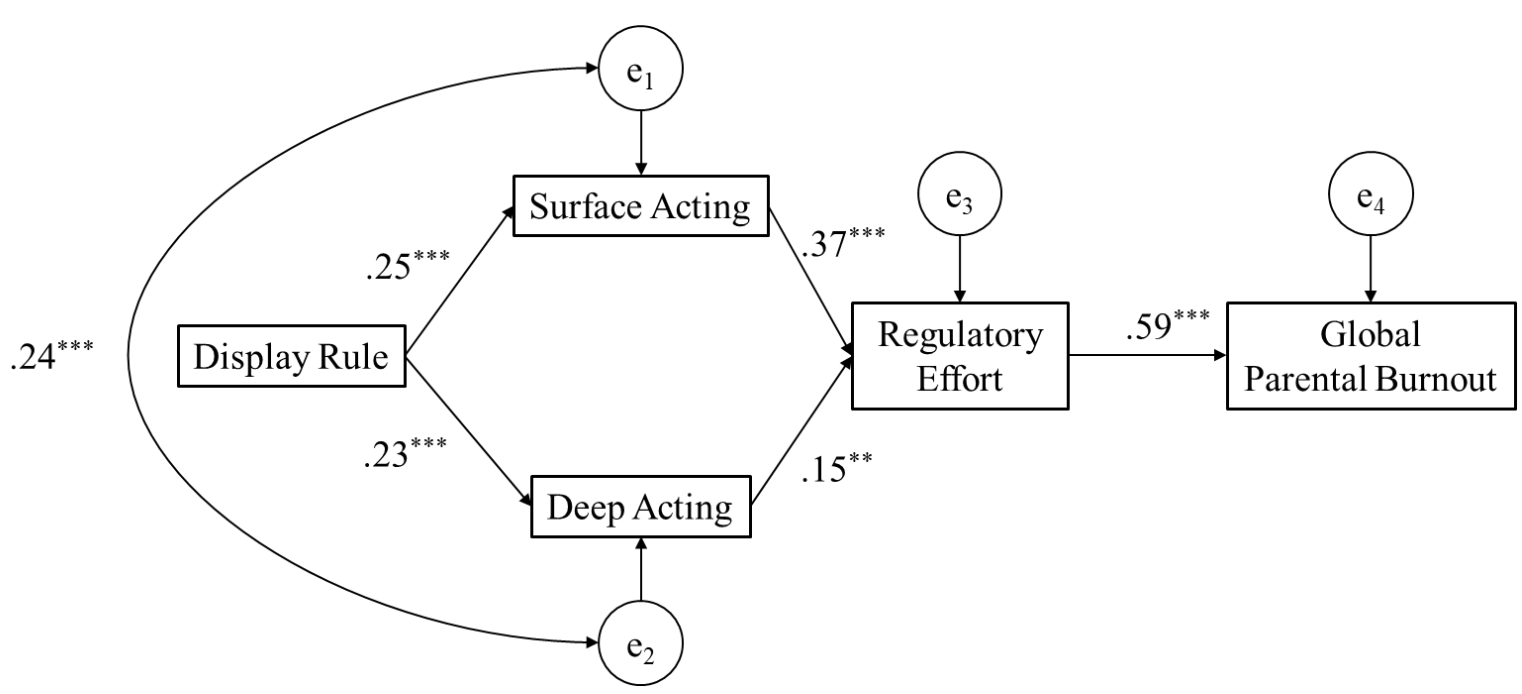

Figure 1. Path analysis model of associations between emotional display rule, surface/deep

acting, regulatory effort, and parental burnout. Coefficients presented are standardized linear regression coefficients.

${ }^{* *} p<.01 .{ }^{* * *} p<.001$. 


\section{References}

Bai, S., Repetti, R. L., \& Sperling, J. B. (2016). Children's expressions of positive emotion are sustained by smiling, touching, and playing with parents and siblings: A naturalistic observational study of family life. Developmental Psychology, 52(1), 88-101. https://doi.org/10.1037/a0039854

Bornstein, M. H. (2015). Children's parents. In Richard M. Lerner (Ed.), Handbook of Child Psychology and Developmental Science: Vol. 4. Ecological settings and processes (7th ed., pp. 55-132). New York, NY: Wiley.

Bretherton, I. (1992). The origins of attachment theory: John Bowlby and Mary Ainsworth. Developmental Psychology, 28(5), 759-775. https://doi.org/10.1037/00121649.28.5.759

Brianda, M. E., Roskam, I., Gross, J. J., Franssen, A., Kapala, F., Gérard, F., \& Mikolajczak, M. (2020). Treating parental burnout: Impact of two treatment modalities on burnout symptoms, emotions, hair cortisol, and parental neglect and violence. Psychotherapy and Psychosomatics. Advanced online publication. https://doi.org/10.1159/000506354

Brotheridge, C. M., \& Grandey, A. A. (2002). Emotional labor and burnout: Comparing two perspectives of "people work.” Journal of Vocational Behavior, 60(1), 17-39. https://doi.org/10.1006/jvbe.2001.1815 
Brotheridge, C. M., \& Lee, R. T. (1998). On the dimensionality of emotional labour: Development and validation of the Emotional Labour Scale. Presented at the First Conference on Emotions in Organizational Life, San Diego, USA.

Brotheridge, C. M., \& Lee, R. T. (2002). Testing a conservation of resources model of the dynamics of emotional labor. Journal of Occupational Health Psychology, 7(1), 57-67. https://doi.org/10.1037/1076-8998.7.1.57

Browne, M. W., \& Cudeck, R. (1992). Alternative ways of assessing model fit. Sociological Methods \& Research, 21(2), 230-258.

Carreras, J., Carter, A. S., Heberle, A., Forbes, D., \& Gray, S. A. O. (2019). Emotion regulation and parent distress: Getting at the heart of sensitive parenting among parents of preschool children experiencing high sociodemographic risk. Journal of Child and Family Studies, 28(11), 2953-2962. https://doi.org/10.1007/s10826-019-01471-z

Chen, Y., Haines, J., Charlton, B. M., \& VanderWeele, T. J. (2019). Positive parenting improves multiple aspects of health and well-being in young adulthood. Nature Human Behaviour, 3(7), 684-691. https://doi.org/10.1038/s41562-019-0602-x

de Looff, P. C., Cornet, L. J. M., Embregts, P. J. C. M., Nijman, H. L. I., \& Didden, H. C. M. (2018). Associations of sympathetic and parasympathetic activity in job stress and burnout: A systematic review. PLoS ONE, 13(10). https://doi.org/10.1371/journal.pone. 0205741 
Dix, T. M. (1991). The affective organization of parenting: Adaptive and maladaptive processes. Psychological Bulletin, 110(1), 3-25.

Gabriel, A. S., Daniels, M. A., Diefendorff, J. M., \& Greguras, G. J. (2015). Emotional labor actors: A latent profile analysis of emotional labor strategies. Journal of Applied Psychology, 100(3), 863-879. https://doi.org/10.1037/a0037408

Goldberg, L. S., \& Grandey, A. A. (2007). Display rules versus display autonomy: Emotion regulation, emotional exhaustion, and task performance in a call center simulation. Journal of Occupational Health Psychology, 12(3), 301-318. https://doi.org/10.1037/1076-8998.12.3.301

Goldin, P. R., McRae, K., Ramel, W., \& Gross, J. J. (2008). The neural bases of emotion regulation: Reappraisal and suppression of negative emotion. Biological Psychiatry, 63(6), 577-586. https://doi.org/10.1016/j.biopsych.2007.05.031

Grandey, A. A. (2000). Emotional regulation in the workplace: A new way to conceptualize emotional labor. Journal of Occupational Health Psychology, 5(1), 95-110.

Grandey, A. A. (2003). When "the show must go on": Surface acting and deep acting as determinants of emotional exhaustion and peer-rated service delivery. Academy of Management Journal, 46(1), 86-96. https://doi.org/10.5465/30040678

Grandey, A. A., Diefendorffand, J. M., \& Rupp, D. E. (Eds.). (2013). Emotional labor in the 21st century: Diverse perspectives on the psychology of emotion regulation at work. 
New York, NY: Routledge.

Gross, J. J. (1998). Antecedent- and response-focused emotion regulation: Divergent consequences for experience, expression, and physiology. Journal of Personality and Social Psychology, 74(1), 224-237. https://doi.org/10.1037/0022-3514.74.1.224

Gross, J. J. (Ed.). (2014). Handbook of Emotion Regulation. New York, NY: Guilford.

Gross, J. J. (2015). The extended process model of emotion regulation: Elaborations, applications, and future directions. Psychological Inquiry, 26(1), 130-137. https://doi.org/10.1080/1047840X.2015.989751

Hochschild, A. R. (1983). The managed heart: Commercialization of human feeling. Berkley, CA: University of California Press.

Hoghughi, M. (2004). Parenting-An introduction. In M. Hoghughi \& N. Long (Eds.), Handbook of parenting: Theory and research for practice (pp. 1-18). London: SAGE.

Hu, L., \& Bentler, P. M. (1998). Fit indices in covariance structure modeling: Sensitivity to underparameterized model misspecification. Psychological Methods, 3(4), 424-453.

Hu, L., \& Bentler, P. M. (1999). Cutoff criteria for fit indexes in covariance structure analysis: Conventional criteria versus new alternatives. Structural Equation Modeling: A Multidisciplinary Journal, 6(1), 1-55.

Hülsheger, U. R., \& Schewe, A. F. (2011). On the costs and benefits of emotional labor: A 
meta-analysis of three decades of research. Journal of Occupational Health Psychology, 16(3), 361-389. https://doi.org/10.1037/a0022876

IBM Corp. (2017). IBM SPSS Statistics for Windows (Version 25). Armonk, NY: IBM Corp. Kammeyer-Mueller, J. D., Rubenstein, A. L., Long, D. M., Odio, M. A., Buckman, B. R., Zhang, Y., \& Halvorsen-Ganepola, M. D. K. (2013). A meta-analytic structural model of dispositonal affectivity and emotional labor. Personnel Psychology, 66(1), 47-90. https://doi.org/10.1111/peps.12009

Kline, R. B. (2011). Principles and practice of structural equation modeling. ( $3^{\text {rd }}$ ed.). New York, NY: Guilford.

Le, B. M., \& Impett, E. A. (2019). Parenting goal pursuit is linked to emotional well-being, relationship quality, and responsiveness. Journal of Social and Personal Relationships, 36(3), 879-904. https://doi.org/10.1177/0265407517747417

Le, B. M., Sakaluk, J. K., Day, L. C., \& Impett, E. A. (2019). How gender, age, and socioeconomic status predict parenting goal pursuit. Journal of Social and Personal Relationships, 36(10), 3313-3338. https://doi.org/10.1177/0265407518818375

Lee, E., Bristow, J., Faircloth, C., \& Macvarish, J. (2014). Parenting Culture Studies. London: Palgrave.

Lim, Y. K., Cho, S. J., Min, S., Park, J. H., \& Park, S. H. (2018). The differential effect of ego-resiliency on the relationship between emotional labor and salivary cortisol level 
in bank clerks. International Journal of Environmental Research and Public Health, 15(11), 2576. https://doi.org/10.3390/ijerph15112576

Manassis, K., Bradley, S., Goldberg, S., Hood, J., \& Swinson, R. P. (1994). Attachment in mothers with anxiety disorders and their children. Journal of the American Academy of Child \& Adolescent Psychiatry, 33(8), 1106-1113.

Maslach, C., Schaufeli, W. B., \& Leiter, M. P. (2001). Job burnout. Annual Review of Psychology, 52(1), 397-422. https://doi.org/10.1146/annurev.psych.52.1.397

McRae, K. (2016). Cognitive emotion regulation: A review of theory and scientific findings. Current Opinion in Behavioral Sciences, 10, 119-124. https://doi.org/10.1016/j.cobeha.2016.06.004

Meeussen, L., \& Van Laar, C. (2018). Feeling pressure to be a perfect mother relates to parental burnout and career ambitions. Frontiers in Psychology, 9, 2113-2113. https://doi.org/10.3389/fpsyg.2018.02113

Mikolajczak, M., Brianda, M. E., Avalosse, H., \& Roskam, I. (2018). Consequences of parental burnout: Its specific effect on child neglect and violence. Child Abuse \& Neglect, 80, 134-145. https://doi.org/10.1016/j.chiabu.2018.03.025

Mikolajczak, M., Gross, J. J., \& Roskam, I. (2019). Parental burnout: What is it and why does it matter? Clinical Psychological Science, 7(6), 1319-1329.

https://doi.org/10.1177/2167702619858430 
Mikolajczak, M., Menil, C., \& Luminet, O. (2007). Explaining the protective effect of trait emotional intelligence regarding occupational stress: Exploration of emotional labour processes. Journal of Research in Personality, 41(5), 1107-1117. https://doi.org/10.1016/j.jrp.2007.01.003

Mikolajczak, M., \& Roskam, I. (2018). A theoretical and clinical framework for parental burnout: The balance between risks and resources $\left(\mathrm{BR}^{2}\right)$. Frontiers in Psychology, 9 , 886. https://doi.org/10.3389/fpsyg.2018.00886

Mikolajczak, M., Tran, V., Brotheridge, C. M., \& Gross, J. J. (2009). Using an emotion regulation framework to predict the outcomes of emotional labor. In Härtel, C., Ashkanasy, N. and Zerbe, W. (Eds.) Research on emotion in organizations: Emotions in groups, organizations and cultures (pp. 245-273). https://doi.org/10.1108/S17469791(2009)0000005013

National Center on Birth Defects and Developmental Disabilities (NCBDD). (n.d.). Positive parenting tips. https://www.cdc.gov/ncbddd/childdevelopment/positiveparenting/index.html

Richards, J. M., \& Gross, J. J. (1999). Composure at any cost? The cognitive consequences of emotion suppression. Personality and Social Psychology Bulletin, 25(8), 1033-1044.

Richards, J. M., \& Gross, J. J. (2000). Emotion regulation and memory: The cognitive costs of keeping one's cool. Journal of Personality and Social Psychology, 79(3), 410-424. 
https://doi.org/10.1037/0022-3514.79.3.410

Rodrigo, M. J. (2010). Promoting positive parenting in Europe: New challenges for the European Society for Developmental Psychology. European Journal of Developmental Psychology, 7(3), 281-294. https://doi.org/10.1080/17405621003780200

Roskam, I., Aguiar, J., Akgun, E., Arikan, G., Artavia, M., Aunola, K., ... Mikolajczak, M. (2020). Parental Burnout Around the Globe: A 40-Country Study. Manuscript submitted for publication.

Roskam, I., Brianda, M.-E., \& Mikolajczak, M. (2018). A step forward in the conceptualization and measurement of parental burnout: The Parental Burnout Assessment (PBA). Frontiers in Psychology, 9, 758. https://doi.org/10.3389/fpsyg.2018.00758

Roskam, I., Raes, M.-E., \& Mikolajczak, M. (2017). Exhausted parents: Development and preliminary validation of the Parental Burnout Inventory. Frontiers in Psychology, 8 , 163. https://doi.org/10.3389/fpsyg.2017.00163

Ryan, R. M., Martin, A., \& Brooks-Gunn, J. (2006). Is one good parent good enough? Patterns of mother and father parenting and child cognitive outcomes at 24 and 36 months. Parenting, 6(2-3), 211-228. https://doi.org/10.1080/15295192.2006.9681306

Sanders, M. R., \& Mazzucchelli, T. G. (2017). The power of positive parenting: Transforming the lives of children, parents, and communities using the triple P system. New York, NY: Oxford University Press. 
Sanz-Vergel, A. I., Rodríguez-Muñoz, A., Bakker, A. B., \& Demerouti, E. (2012). The daily spillover and crossover of emotional labor: Faking emotions at work and at home. Journal of Vocational Behavior, 81(2), 209-217. https://doi.org/10.1016/j.jvb.2012.07.003

Sayre, G. M., Grandey, A. A., \& Chi, N.-W. (2019). From cheery to “cheers"? Regulating emotions at work and alcohol consumption after work. Journal of Applied Psychology. Advance online publication. https://doi.org/10.1037/ap10000452

Sorkkila, M., \& Aunola, K. (2020). Risk factors for parental burnout among Finnish parents: The role of socially prescribed perfectionism. Journal of Child and Family Studies, 29(3), 648-659. https://doi.org/10.1007/s10826-019-01607-1

StataCorp. (2019). Stata Statistical Software (Version Release 16). College Station, TX: StataCorp. LLC.

Strack, F., Martin, L. L., \& Stepper, S. (1988). Inhibiting and facilitating conditions of the human smile: A nonobtrusive test of the facial feedback hypothesis. Journal of Personality and Social Psychology, 54(5), 768-777.

Verhellen, E. (2000). Convention on the rights of the child: Background, motivation, strategies, main themes ( $3^{\text {rd }}$ revised). Leuven; Apeldoorn: Garant.

Wharton, A. S. (2009). The sociology of emotional labor. Annual Review of Sociology, 35(1), 147-165. https://doi.org/10.1146/annurev-soc-070308-115944 